\title{
HYDROLYSIS OF HYDROXYETHYL METHYLCELLULOSE WITH PERCHLORIC ACID AND DETERMINATION OF CHEMICAL STRUCTURE VIA ${ }^{13} \mathrm{C}$ NMR SPECTROSCOPY
}

\author{
SERGEY G. KOSTRYUKOV, PAVEL S. PETROV, \\ VALENTIN A. KALYAZIN, WAJAHAT ULLAH, VERONICA S. TEZIKOVA, \\ ARTYOM A. ODNOPOLOV, YULIYA YU. MASTEROVA and \\ DHURGHAM HANI KADHIM ALALWAN \\ National Research Mordovia State University, Saransk, Russia \\ \Corresponding author: Sergey G. Kostryukov, kostryukov_sg@mail.ru
}

Received November 10, 2019

\begin{abstract}
Hydroxyethyl methylcellulose (HEMC) is widely used in the pharmaceutical, food and construction industries to impart desirable qualities, such as rheology, thixotropy, anti-sedimentation and water retention, to water-dispersible systems. The main application area of the mentioned cellulose ether is in the creation of different construction compositions, in particular, dry mixtures. We studied the hydrolysis of three samples of HEMC, with different degrees of polymerization, under the action of aqueous solutions of perchloric acid $\left(\mathrm{HClO}_{4}\right)$ at a concentration of $1 \%, 2 \%, 3 \%$ and $4 \%$ and temperature of $80,90,100$ and $110^{\circ} \mathrm{C}$ in a microwave reactor. The completeness of hydrolysis was estimated by the disappearance of the acetal carbon atom signal in the ${ }^{13} \mathrm{C}$ NMR spectrum. It has been shown that the increase in temperature affects less, while the concentration of the acid has the greatest influence on the rate of hydrolysis, and the reaction time is even shorter. Using comparative analysis of the completeness of hydrolysis of various HEMC samples, it was possible to assess the degrees of polymerization of the cellulose ethers qualitatively. The structure of the hydrolysis products was studied by ${ }^{13} \mathrm{C}$ NMR spectroscopy, as a result, the substitution parameters at the 2, 3 and 6 positions ( $\mathrm{DS}^{\mathrm{C}-2}, \mathrm{DS}^{\mathrm{C}-3}$ and $\mathrm{DS}^{\mathrm{C}-6}$ ) and the number of methyl $\left(\mathrm{DS}^{\mathrm{Me}}\right)$ and hydroxyethyl groups $\left(\mathrm{DS}^{\mathrm{HE}}\right)$ were determined, and the total degree of substitution ( $\mathrm{DS}^{\text {total }}$ ) was calculated. Thus, the optimum conditions for the hydrolysis of hydroxyethyl methylcellulose were selected and defined by the polymer structure, including both distribution of substituents at different positions and the number of each type of substituents in the anhydroglucose unit.
\end{abstract}

Keywords: hydrolysis, NMR spectra, cellulose, hydroxyethyl methylcellulose, perchloric acid, degree of substitution, substituent distribution, integral intensity

\section{INTRODUCTION}

Nowadays, mixed cellulose ethers are widely used in various branches of industry. ${ }^{1-3}$ One of the most significant and widely used representatives of this group of chemical substances is hydroxyethyl methylcellulose (HEMC). For example, HEMC is applied for the production of ceramic tile adhesive mortars, ${ }^{4}$ Portland cement ${ }^{5}$ and dry plaster mixture formulas. ${ }^{6}$ The usage of HEMC in water-disperse systems greatly increases their viscosity and, as a result, improves the stability and homogeneity of the produced consistence. ${ }^{7}$ Also, polymers based on cellulose ethers are used in the development of amorphous solid pharmaceutical dispersions. ${ }^{8}$
The ability of HEMC to increase the viscosity of water-disperse systems is the result of the presence of methyl and hydroxyethyl radicals at certain positions of the glucopyranose cycle. ${ }^{9}$ Cellulose etherification leads to the destruction of intermolecular hydrogen bonds between cellulose chains and gives the cellulose ether the ability to dissolve in water.

Manufacturers of HEMC and other cellulose ethers typically offer products with different substitution parameters, properties and purity. For this reason, the main consumers of this product are interested in creating high-performance methods for determining the structural characteristics of HEMC, the most important of 
which are the degree of substitution (DS) and molar substitution (MS). ${ }^{10}$ Structural fragments of HEMC molecules are shown in Figure 1.

In accordance with the parameters of cellulose etherification by the treatment with ethylene oxide and methyl chloride under alkaline conditions, hydroxyethyl methylcellulose is produced with different distribution of substituents in the anhydroglucose unit. A scheme for the synthesis of hydroxyethyl methylcellulose is shown in Figure 2.

At present, various analytical methods are used to determine the substitution characteristics of cellulose ethers. ${ }^{10}$ Most often, chromatographic methods are used to determine their structural characteristics. Since the distribution and number of the substituents have a great impact on the properties of cellulose ethers, the determination of substitution parameters is one of the most important tasks in the chemistry of cellulose derivatives.

The structure of cellulose ethers, including HEMC, is described by the degree of substitution (DS) and the molar substitution (MS). Each anhydroglucose unit in the cellulose chain has three hydroxyl groups available for modification. Thus, if all three available positions of each unit are substituted, the DS is designated as 3; if, on the average, two positions of each ring reacted, the DS is 2. The term DS is reserved for substituents that block the reactive hydroxyl groups (methoxyl groups). The substitution is described by the MS, i.e. the number of moles of hydroxyethoxyl group per mole of anhydroglucose unit in the chain. ${ }^{10}$

The easiest way to determine molar substitution (MS) is the Zeisel method. This method allows the quantitative determination of the number of alkyl groups connected to the oxygen atom of an ether or ester by heating the mixture of the substrate with hydroiodic acid (HI) and trapping the evolving alkyl iodide with silver nitrate. ${ }^{11}$ The original Zeisel determination has been modified, and after treatment of cellulose ether by hydroiodic acid, the amount of produced alkyl iodide was measured with the help of gasliquid $^{12-13}$ or high-performance liquid chromatography. ${ }^{14}$ The determination of substitution parameters in methyl hydroxypropylcellulose is carried out through GLC-MS (gas-liquid chromatography-mass spectrometry) analysis of the products generated after chemical processing of the cellulose ether, including deuteromethylation, partial depolymerization and reductive amination with $p$ aminobenzoic acid. ${ }^{15}$

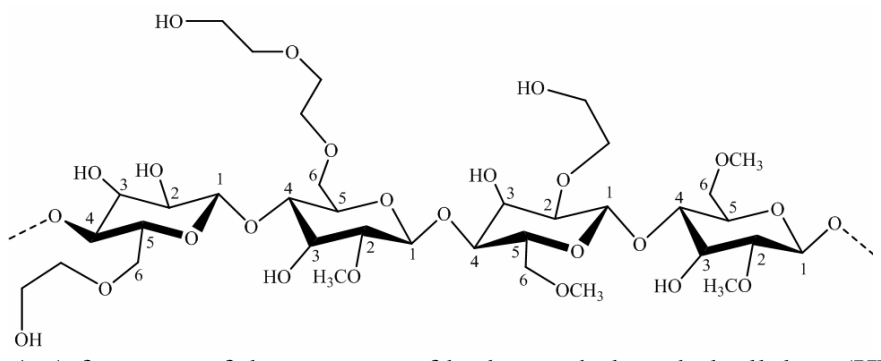

Figure 1: A fragment of the structure of hydroxyethyl methylcellulose (HEMC)
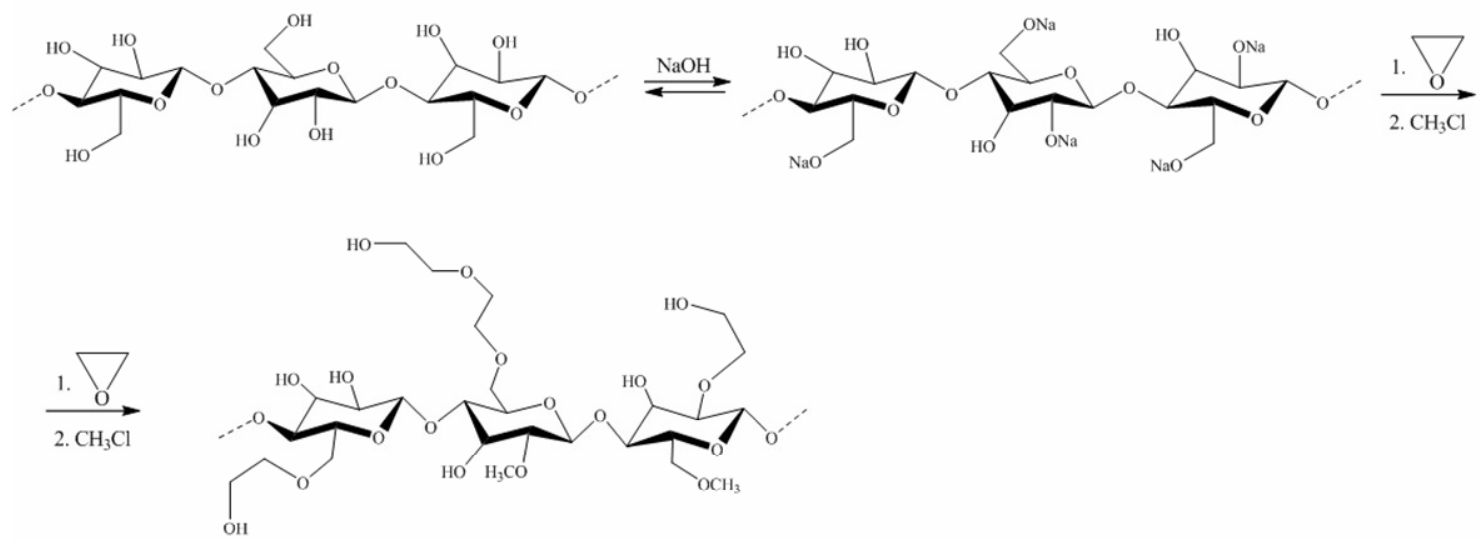

Figure 2: Scheme for the production of hydroxyethyl methylcellulose 
The structure of hydroxyethyl methylcellulose was investigated in the following way: the level of substitution by methyl radicals was determined after hydrolysis, reduction and acetalization via GLC-MS analysis; the level of substitution by hydroxyethyl radicals $\quad-\quad$ after perdeuteromethylation, partial acid hydrolysis reductive amination with propylamine and subsequent permethylation with generation of completely O-alkylated and N-alkylated derivatives was determined by laser desorptive ionization mass spectrometry. ${ }^{16}$ Thus, all chromatographic and mass-spectrometric methods require preliminary chemical processing, often including several stages and also the use of a standard substance.

In recent years, NMR spectroscopy has been widely used for research on the structure of cellulose ethers. The investigation of methyl-, hydroxypropyl- and methyl hydroxypropylcellulose was conducted by ${ }^{13} \mathrm{C}$ NMR spectroscopy of their aqueous solution. ${ }^{17}$ Ethyl hydroxyethylcellulose was investigated by ${ }^{13} \mathrm{C}$ NMR spectroscopy in solution and in a solid state. ${ }^{18}$ The structure of methylcellulose was studied by solid state $\mathrm{NMR}{ }^{13} \mathrm{C}$ to establish the value of DS (degree of substitution). ${ }^{19}$ In a number of papers discussing the determination of substitution parameters, ${ }^{1} \mathrm{H}$ and ${ }^{13} \mathrm{C}$ NMR spectroscopy of the hydrolysis products of cellulose ethers was used: by ${ }^{13} \mathrm{C}$ NMR spectroscopy, partially depolymerized samples of hydroxyethyl-, hydroxypropyl and hydroxyethyl methylcelluloses were investigated, ${ }^{20}$ acid hydrolysis of hydroxyethyl methylcellulose under the action of sulfuric acid being used, ${ }^{21}$ and in the readings - enzymatic hydrolysis of hydroxyl ethyl cellulose was analyzed. ${ }^{22}$ On the whole, it is possible to claim that for the analysis of the structure of cellulose ethers, ${ }^{13} \mathrm{C}$ NMR spectroscopy of both polymers and the products of their hydrolysis has been actively used in recent years. Especially often, it happens in the cases when highly viscous solutions are produced during the dissolution of cellulose ether. Recording the NMR spectra for these samples is difficult because of the significant increase in the spin-lattice relaxation time and the decrease in the resonance signal. On the basis of ${ }^{13} \mathrm{C}$ NMR (CPMAS) results, a relatively easy nondestructive method for determining the substitution parameters for cellulose ethers of different structure is considered. ${ }^{23}$ However, this method does not allow determining the distribution of substituents according to the different positions of the glucopyranose unit. This article provides data on the determination of the substitution characteristics for different commercial samples of hydroxyethyl methylcellulose (HEMC) with different physical properties, namely, with various viscosity of aqueous solutions. It is worth mentioning that, in spite of a large number of papers concerning the determination of the substitution parameters for different cellulose ethers, the analysis of methyl hydroxyethylcellulose is considered insufficient.

In this paper, the content of substituents in several samples of HEMC was determined by ${ }^{13} \mathrm{C}$ NMR spectroscopy of the products after acidcatalyzed hydrolysis of the polymer under the action of perchloric acid $\left(\mathrm{HClO}_{4}\right)$. The obtained results were compared with the data stated from the manufacturer of HEMC, which indicated high accuracy of the method.

Previously, ${ }^{20,21}$ we showed that accurate information on the assignment of substituents in the anhydroglucose unit of the hydroxyethyl methylcellulose can be obtained on the basis of ${ }^{13} \mathrm{C}$ NMR spectra of the products after acidcatalyzed hydrolysis. In these studies, a 35\% solution of $\mathrm{H}_{2} \mathrm{SO}_{4}$ was used for hydrolysis, which caused several difficulties, viz. requirement of acid neutralization after hydrolysis and formation of furfural derivatives as by-products. Therefore, the aim of the present study has been the modification of the method to find milder hydrolysis conditions, namely, a decrease in the concentration of the acid, with the simplification of its subsequent removal, and lower reaction temperature. In this work, we propose to use a $4 \%$ solution of $\mathrm{HClO}_{4}$ in water and a microwave reactor for the hydrolysis of cellulose ethers, which can significantly accelerate and simplify the process of hydrolytic cleavage of cellulose ether.

\section{EXPERIMENTAL}

\section{Materials and research methods}

For the study, three samples of hydroxyethyl methylcellulose solutions, with different viscosity, were selected. The list of investigated samples and their common characteristics is shown in Table 1. All the initial samples were in the form of finely divided polymeric white powder.

The ${ }^{13} \mathrm{C}$ NMR spectra of HEMC I-III hydrolysates and model compounds were recorded on a JEOL JNMECX400 spectrometer $(9.39 \mathrm{~T}, 100.5 \mathrm{MHz})$ for solutions in $\mathrm{D}_{2} \mathrm{O} / \mathrm{H}_{2} \mathrm{O}\left(50-60 \mathrm{mg}\right.$ in $0.7 \mathrm{~mL}$ of $\mathrm{D}_{2} \mathrm{O}$ and $\mathrm{H}_{2} \mathrm{O}$ in a ratio of $9: 1$ ), at a frequency of $100.5 \mathrm{MHz}$, 
using a standard pulse sequence with an increase in the relaxation time $\left(\mathrm{T}_{1}\right)$ to 5 seconds, without using the nuclear Overhauser effect (NOE), at $40{ }^{\circ} \mathrm{C}$. These conditions for recording the NMR spectra were selected in accordance with a series of experiments, with different pulse durations, in order to obtain the same signal intensity of different types of carbon atoms in standard samples of D-glucose, methyl- $\beta$-Dglucopyranoside and cellobiose. The signals of sodium salt of 4,4-dimethyl-4-silapentane-1-sulfonic acid were used as reference in the spectra.

The spectra were processed using the ACD/NMR Processor Academic Edition program, Ver. 12.01.

\section{Hydrolysis of cellulose ethers}

Hydrolysis of hydroxyethyl methylcellulose samples I-III was performed by the following procedure: $0.20 \mathrm{~g}$ of cellulose ether was dissolved in $10 \mathrm{~mL}$ of $\mathrm{HClO}_{4}$ solution at a concentration from $1 \%$ to $4 \%$, and was heated in a microwave reactor (Monowave 300, Anton Paar) at 80, 90, 100, $110{ }^{\circ} \mathrm{C}$ for 60 or 90 minutes. After completion of the process, the reaction mixture was neutralized with $\mathrm{KOH}$. The resulting solution was evaporated on a rotary evaporator to half of the initial volume, and precipitated $\mathrm{KClO}_{4}$ was filtered off. The mother liquor was evaporated to dryness in vacuo.

The resulting residue was dissolved in $1 \mathrm{~mL}$ of $\mathrm{D}_{2} \mathrm{O}$, centrifuged, and analyzed by ${ }^{13} \mathrm{C}$ NMR spectroscopy. A control experiment of D-glucose heating with $4 \%$ solution of $\mathrm{HClO}_{4}$ at $110{ }^{\circ} \mathrm{C}$ showed that glucose does not undergo any chemical reactions under these conditions.

\section{RESULTS AND DISCUSSION}

The correction factors $(\alpha)$ for the intensity of the signals of different carbon atom types were calculated (Table 2) on the basis of the ${ }^{13} \mathrm{C}$ NMR spectra of D-glucose and methyl- $\beta-D$ glucopyranoside as standard samples. ${ }^{25,26}$

The optimum conditions of hydrolysis were found according to the analysis of ${ }^{13} \mathrm{C}$ NMR spectra of the HEMC I-III hydrolysates obtained at different reaction time, temperature and concentration of $\mathrm{HClO}_{4}$ solution. As an example,
Figure 3 shows the ${ }^{13} \mathrm{C}$ NMR spectra of the hydrolyzed HEMC II samples obtained at different acid concentrations.

As can be seen from the spectra shown in Figure 3, at the same duration of hydrolysis and temperature, an increase of the acid concentration leads to the disappearance of the signal in the field $\sim 102.6 \mathrm{ppm}$, corresponding to an acetal atom at C-1. Simultaneously, the intensity increases in the case of the signals at $\sim 96.0 \mathrm{ppm}$ and 92.3 ppm, corresponding to $\alpha$ - and $\beta$-hemiacetal atom $\mathrm{C}-1$, respectively. In addition, an improvement of the signal-to-noise ratio is observed, which is apparently caused by a decrease of the viscosity of the solutions.

Thus, the completeness of hydrolysis can be estimated by the absence of the acetal carbon atom signal $(\sim 102.6 \mathrm{ppm})$ in the spectra. The content of monosaccharides in molar percent can be determined by Equation 1 as the ratio of the total intensity of $\beta$ - and $\alpha$-hemiacetal carbon atom signals $\left(\beta-I_{95.7-96.2}, \alpha-I_{92.1-92.4}\right)$ to the sum of intensities of hemiacetal and acetal $\left(\mathrm{I}_{102.0-102.8}\right)$ carbon atom signals:

$$
\omega=\frac{I_{95.7-96.2}+I_{92.1-92.4}}{I_{95.7-96.2}+I_{92.1-92.4}+I_{102.0-102.8}} \times 100 \%
$$

Hereinafter, the parameters with the general designation $I_{n-m}$ mean the integral intensity of the corresponding spectral area.

Table 3 shows the mole percent $(\omega, \%)$ of the monosaccharide products in the hydrolysates depending on the duration of hydrolysis ( $\mathrm{t}, \mathrm{min}$ ), reaction temperature $\left(\mathrm{T},{ }^{\circ} \mathrm{C}\right)$ and the concentration of perchloric acid (c, \%).

Figure 4 shows the dependence of the conversion of HEMC to monosaccharides on the reaction temperature and acid concentration. Figure 5 presents the conversion of HEMC I-III into monosaccharides as a function of $\mathrm{HClO}_{4}$ concentration at different temperatures.

Table 1

Characteristics of studied samples of hydroxyethyl methylcellulose ${ }^{24}$

\begin{tabular}{|c|c|c|c|c|}
\hline \multirow[t]{2}{*}{ Designation } & \multirow{2}{*}{$\begin{array}{c}\text { Heppler viscosity at } 25^{\circ} \mathrm{C} \\
\text { (2\% aqueous solution), } \\
\text { MPas }\end{array}$} & \multicolumn{2}{|c|}{$\begin{array}{c}\text { Content of groups } \\
\text { (WT, \%) }\end{array}$} & \multirow[t]{2}{*}{ DS } \\
\hline & & $\mathrm{MeO}$ & $\mathrm{HOCH}_{2} \mathrm{CH}_{2} \mathrm{O}$ & \\
\hline I (Tylose® MH 200 YP2) & 200 & $18.0-22.0$ & $4.0-12.0$ & $1.40 \pm 0.20$ \\
\hline II (Tylose® MH 30000 YP4) & 30000 & $19.0-25.0$ & $5.0-13.0$ & $1.50 \pm 0.20$ \\
\hline III (Tylose® MH 150000 P4) & 150000 & $20.0-26.0$ & $6.0-14.0$ & $1.70 \pm 0.20$ \\
\hline
\end{tabular}


Hydroxyethyl methylcellulose

Table 2

Values of correction intensity factors for carbon atoms of the pyranose ring and $\mathrm{CH}_{2}$ and $\mathrm{CH}_{3}$ groups

\begin{tabular}{lccccccccc}
\hline Carbon atom type & C-1 (hemiacetal) & C-1 (acetal) & C-2 & C-3 & C-4 & C-5 & C-6 & $\mathrm{CH}_{2}$ & $\mathrm{CH}_{3}$ \\
\hline Relative intensity & 1.00 & 1.00 & 1.03 & 1.01 & 1.03 & 1.02 & 1.00 & 1.00 & 1.38 \\
Correction factors $(\alpha)$ & 1.00 & 1.00 & 0.97 & 0.99 & 0.97 & 0.98 & 1.00 & 1.00 & 0.72 \\
\hline
\end{tabular}

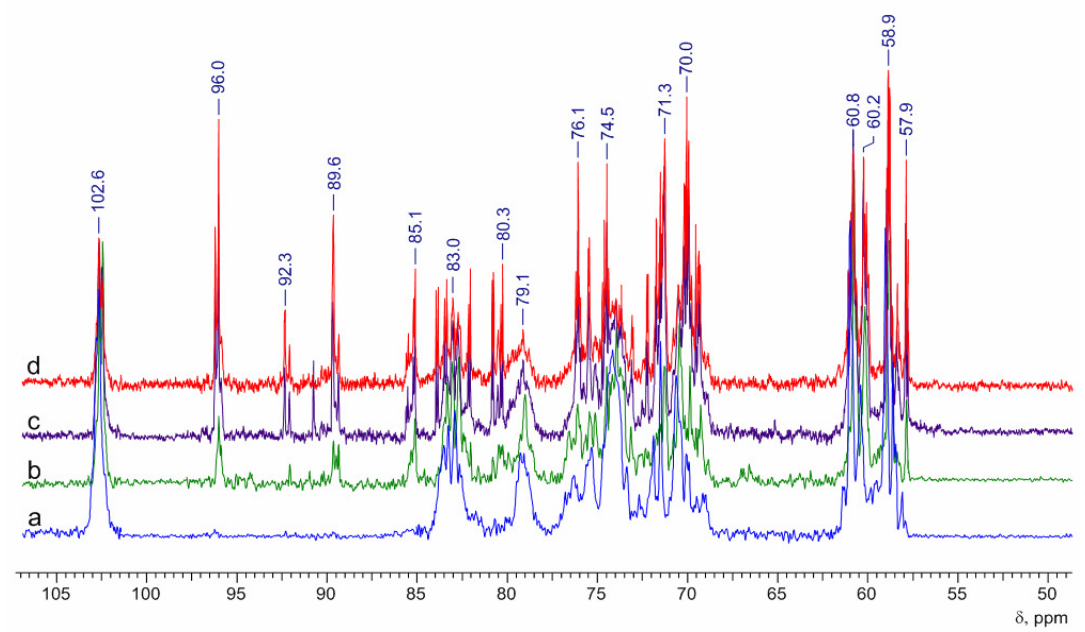

Figure $3:{ }^{13} \mathrm{C}$ NMR spectra of the products of acid-catalyzed hydrolysis of HEMC II in $\mathrm{D}_{2} \mathrm{O} / \mathrm{H}_{2} \mathrm{O}$ at different concentrations of $\mathrm{HClO}_{4}\left(60 \mathrm{~min}, 90{ }^{\circ} \mathrm{C}\right): \mathrm{a}-1 \% \mathrm{HClO}_{4}, \mathrm{~b}-2 \% \mathrm{HClO}_{4}, \mathrm{c}-3 \% \mathrm{HClO}_{4}, \mathrm{~d}-4 \% \mathrm{HClO}_{4}$

As can be seen from the charts, increasing the reaction temperature for HEMC II from $80{ }^{\circ} \mathrm{C}$ to $110{ }^{\circ} \mathrm{C}$ for the same time (t) and concentration (c) (e.g., $\mathrm{t}=90 \mathrm{~min}$ ) leads to increasing the conversion: for $1 \%$ solution of $\mathrm{HClO}_{4}$ - by $22 \%$, for $2 \%$ - by $50 \%$, for $3 \%$ - by $95 \%$, for $4 \%-$ $100 \%$. Increasing the reaction time under otherwise equal conditions (temperature and concentration) affects somewhat less the conversion, for example, in the case of HEMC II at $100{ }^{\circ} \mathrm{C}$ and $3 \% \mathrm{HClO}_{4}$ changing the reaction time from 60 minutes to 90 minutes results in increased conversion ( $18 \%$ only).

Thus, it can be concluded that the greatest impact on the completeness of the hydrolysis process is exerted by the concentration of $\mathrm{HClO}_{4}$ : when it increases from $1 \%$ to $4 \%$, the conversion of HEMC to monomers increases and reaches $100 \%$ at a reaction temperature of 100 to $110{ }^{\circ} \mathrm{C}$ (Fig. 5).

When comparing the obtained data with the results of other studies, ${ }^{20,21}$ where sulfuric acid was used for hydrolysis, it becomes apparent that the use of $\mathrm{HClO}_{4}$ has several advantages: reducing the acid concentration, simplifying the processing procedures of the reaction mixture and reducing the hydrolysis time. A higher catalytic ability of $\mathrm{HClO}_{4}$ is realized due to its significantly higher acidity $\left(\mathrm{pK}_{\mathrm{a}}=-15.2\right)^{27}$ in comparison with that of $\mathrm{H}_{2} \mathrm{SO}_{4}\left(\mathrm{pK}_{\mathrm{a} 1}=-2.8 ; \mathrm{pK}_{\mathrm{a} 2}=1.92\right) .{ }^{28}$

Thus, in this work, we used $\mathrm{HClO}_{4}$ to hydrolyze cellulose ethers for the first time, and we have found optimal conditions for complete hydrolysis of HEMC. The products of hydrolysis are glucose derivatives with various substitution, formed by splitting the $\beta(1-4)$-glycosidic bond. Having in mind manufacturers' data on the total degree of substitution (DS), we supposed that the anhydroglucose unit cannot be substituted at more than 2 positions at a time, therefore, mainly monosubstituted and disubstituted glucose derivatives will be present in the reaction mixture. The mentioned derivatives of glucose that can be formed by the hydrolysis of HEMC are presented in Figure 6. Moreover, the configuration of the C1 atom can be related to both $\alpha$ - and $\beta$-forms. 


\section{SERGEY G. KOSTRYUKOV et al.}

Table 4 lists the chemical shift of carbon atoms of the expected hydrolysis products 1-9, calculated using the BIOPSEL program. ${ }^{25,26}$ The algorithm of the BIOPSEL software greatly exceeds the quantum mechanical approaches used for NMR studies both in the prediction accuracy of the ${ }^{13} \mathrm{C}$ NMR chemical shifts of carbohydrates in aqueous solutions and in terms of speed. ${ }^{26}$

Table 3

Dependence of HEMC conversion to monosaccharides on concentration of $\mathrm{HClO}_{4}(\mathrm{c}, \%)$, duration of hydrolysis (t, $\min )$ and reaction temperature $\left(\mathrm{T},{ }^{\circ} \mathrm{C}\right)$

\begin{tabular}{|c|c|c|c|c|c|}
\hline \multirow{2}{*}{$\mathrm{c}\left(\mathrm{HClO}_{4}\right), \%$} & \multirow{2}{*}{$\mathrm{t}, \mathrm{min}$} & \multirow{2}{*}{$\mathrm{T},{ }^{\circ} \mathrm{C}$} & \multicolumn{3}{|c|}{$\omega, \%$} \\
\hline & & & HEMC I & HEMC II & HEMC III \\
\hline \multirow{8}{*}{1} & \multirow{4}{*}{60} & 80 & 6 & 3 & 1 \\
\hline & & 90 & 11 & 8 & 6 \\
\hline & & 100 & 17 & 12 & 10 \\
\hline & & 110 & 24 & 18 & 17 \\
\hline & \multirow{4}{*}{90} & 80 & 7 & 6 & 4 \\
\hline & & 90 & 12 & 11 & 8 \\
\hline & & 100 & 19 & 17 & 15 \\
\hline & & 110 & 27 & 22 & 20 \\
\hline \multirow{8}{*}{2} & \multirow{4}{*}{60} & 80 & 11 & 8 & 6 \\
\hline & & 90 & 22 & 16 & 14 \\
\hline & & 100 & 37 & 32 & 25 \\
\hline & & 110 & 65 & 44 & 38 \\
\hline & \multirow{4}{*}{90} & 80 & 16 & 11 & 8 \\
\hline & & 90 & 29 & 21 & 16 \\
\hline & & 100 & 41 & 34 & 30 \\
\hline & & 110 & 72 & 50 & 46 \\
\hline \multirow{8}{*}{3} & \multirow{4}{*}{60} & 80 & 20 & 16 & 14 \\
\hline & & 90 & 36 & 32 & 29 \\
\hline & & 100 & 57 & 49 & 43 \\
\hline & & 110 & 86 & 66 & 59 \\
\hline & \multirow{4}{*}{90} & 80 & 37 & 24 & 20 \\
\hline & & 90 & 57 & 41 & 35 \\
\hline & & 100 & 76 & 67 & 58 \\
\hline & & 110 & 100 & 95 & 80 \\
\hline \multirow{8}{*}{4} & \multirow{4}{*}{60} & 80 & 46 & 32 & 24 \\
\hline & & 90 & 66 & 51 & 46 \\
\hline & & 100 & 86 & 76 & 68 \\
\hline & & 110 & 100 & 100 & 90 \\
\hline & \multirow{4}{*}{90} & 80 & 58 & 43 & 38 \\
\hline & & 90 & 80 & 62 & 58 \\
\hline & & 100 & 100 & 89 & 79 \\
\hline & & 110 & 100 & 100 & 100 \\
\hline
\end{tabular}



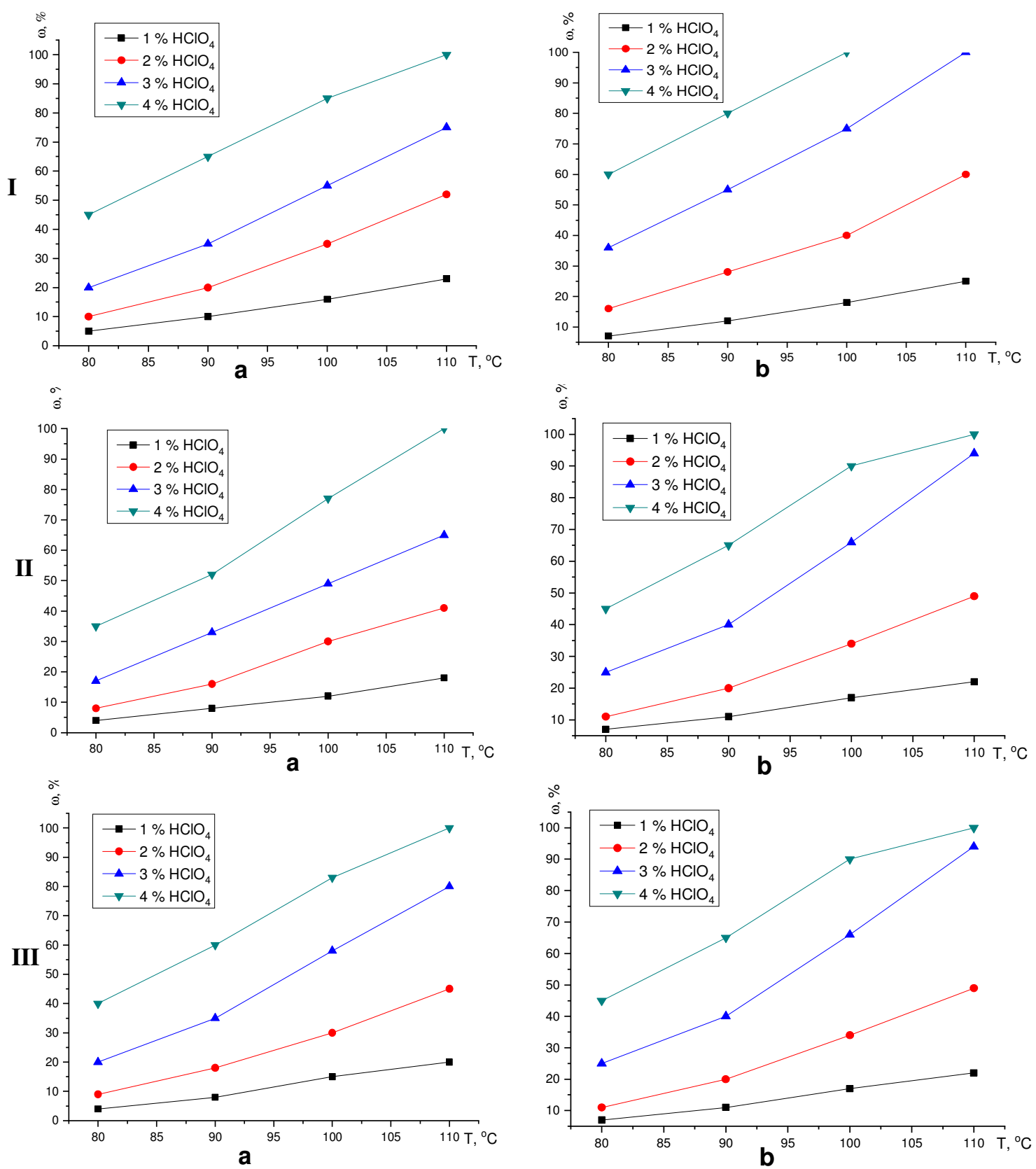

Figure 4: Dependence of HEMC I-III conversion into monosaccharides on reaction temperature at different reaction times: $a-60 \min ; b-90 \min$ 


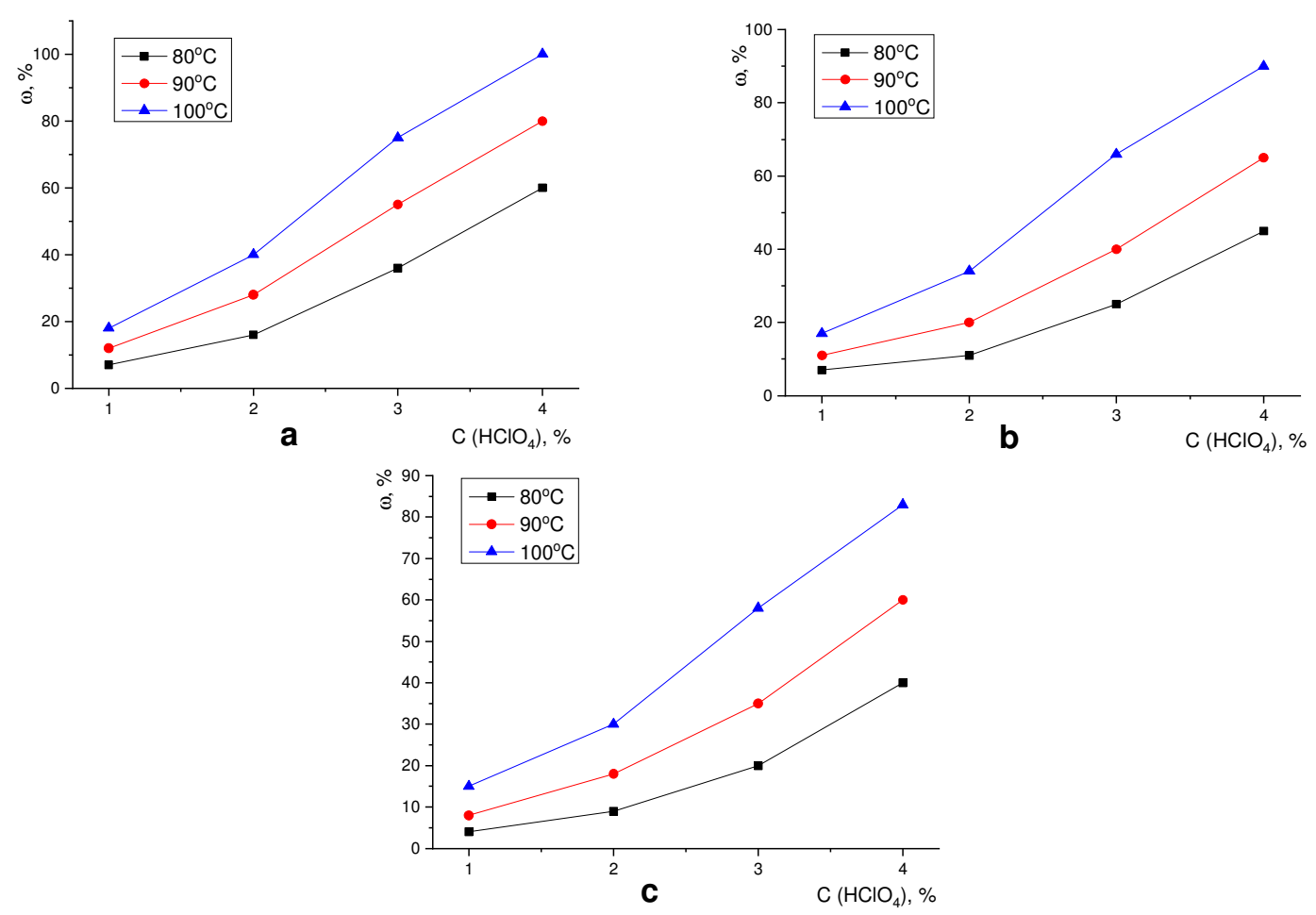

Figure 5: Dependence of HEMC conversion into monosaccharides on concentration of $\mathrm{HClO}_{4}$ at different temperatures: a - HEMC I; b - HEMC II; c - HEMC III

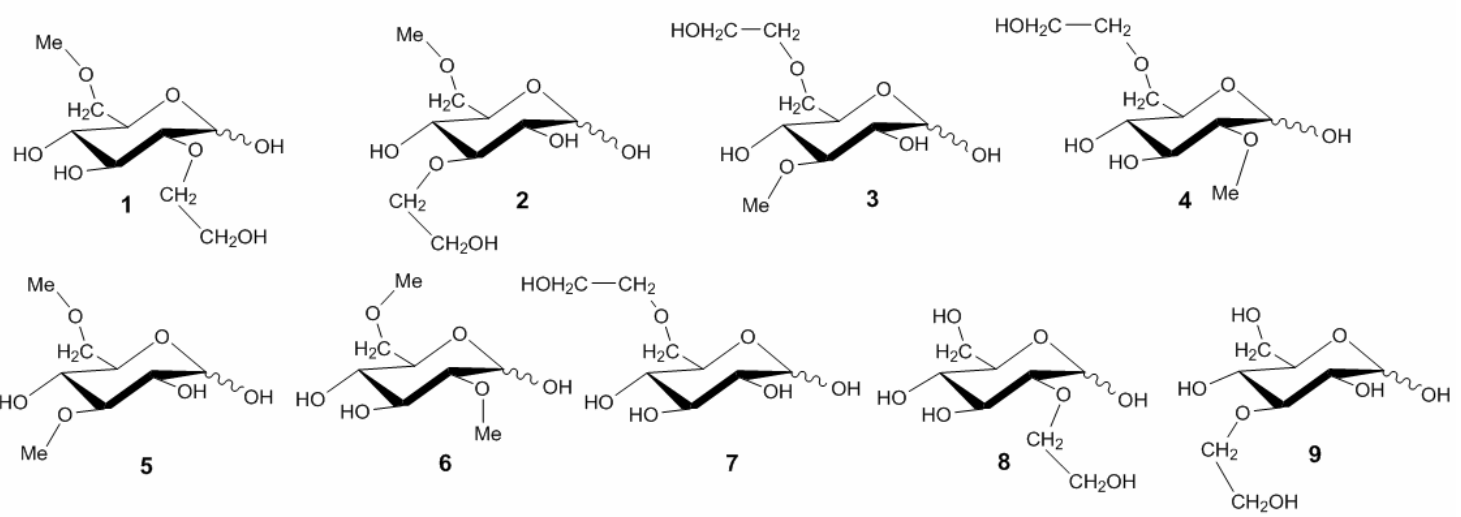

Figure 6: Structure of glucose derivatives obtained after hydrolysis of HEMC samples

Table 4

Calculated ${ }^{13} \mathrm{C}$ NMR spectra of compounds $1-9$

\begin{tabular}{|c|c|c|c|c|c|c|c|c|c|}
\hline \multirow{2}{*}{ Compound } & \multicolumn{2}{|c|}{$\mathrm{C}-1, \mathrm{ppm}$} & \multirow{2}{*}{$\begin{array}{l}\text { C-2, } \\
\text { ppm }\end{array}$} & \multirow{2}{*}{$\begin{array}{l}\text { C-3, } \\
\text { ppm }\end{array}$} & \multirow{2}{*}{$\begin{array}{l}\text { C-4, } \\
\text { ppm }\end{array}$} & \multirow{2}{*}{$\begin{array}{l}\text { C-5, } \\
\text { ppm }\end{array}$} & \multirow{2}{*}{$\begin{array}{l}\text { C-6, } \\
\text { ppm }\end{array}$} & \multirow{2}{*}{$\begin{array}{l}\mathrm{CH}_{3}, \\
\mathrm{ppm}\end{array}$} & \multirow{2}{*}{$\begin{array}{c}\mathrm{CH}_{2} \mathrm{CH}_{2}, \\
\mathrm{ppm}\end{array}$} \\
\hline & $\alpha-$ & $\beta-$ & & & & & & & \\
\hline 1 & 92.1 & 96.2 & 90.0 & 75.4 & 72.1 & 78.8 & 72.3 & 59.6 & $71.0 ; 72.8$ \\
\hline 2 & 93.0 & 96.1 & 73.8 & 85.4 & 69.6 & 78.1 & 72.3 & 59.6 & $62.4 ; 72.8$ \\
\hline 3 & 93.0 & 96.1 & 73.5 & 85.0 & 69.3 & 78.4 & 71.8 & 57.7 & $70.6 ; 61.3$ \\
\hline 4 & 90.5 & 96.0 & 91.2 & 75.1 & 72.1 & 76.5 & 71.8 & 57.7 & $70.6 ; 61.3$ \\
\hline 5 & 92.1 & 96.8 & 73.5 & 84.6 & 69.3 & 79.1 & 72.3 & 59.6 (at C-6); 57.7 (at C-3) & - \\
\hline 6 & 92.1 & 96.1 & 90.2 & 75.1 & 72.1 & 78.8 & 72.3 & 59.6 (at C-6); 57.7 (at C-2) & - \\
\hline 7 & 92.8 & 96.0 & 72.2 & 72.6 & 71.8 & 75.5 & 71.8 & $70.6 ; 61.3$ & \\
\hline 8 & 91.5 & 96.3 & 90.0 & 75.4 & 71.8 & 78.3 & 60.2 & $71.0 ; 62.8$ & \\
\hline 9 & 92.8 & 95.2 & 73.8 & 85.4 & 69.3 & 77.5 & 60.2 & $72.8 ; 62.4$ & \\
\hline
\end{tabular}




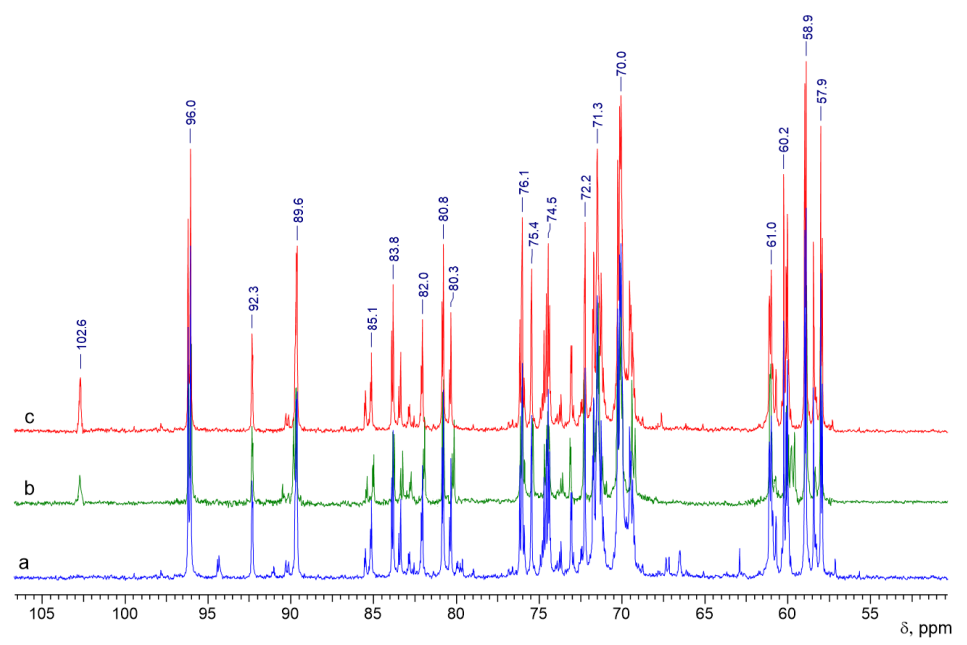

Figure 7: ${ }^{13} \mathrm{C}$ NMR spectra of the products of acid-catalyzed hydrolysis of HEMC I-III samples in $\mathrm{D}_{2} \mathrm{O} / \mathrm{H}_{2} \mathrm{O}$

$\left(3 \% \mathrm{HClO}_{4}, 90 \mathrm{~min}, 110^{\circ} \mathrm{C}\right): \mathrm{a}$ - HEMC I sample, b - HEMC II sample, c - HEMC III sample

The ${ }^{13} \mathrm{C}$ NMR spectra of the products of acidcatalyzed hydrolysis of the studied HEMC samples are quite complex and contain a large number of signals in the region of $65-100 \mathrm{ppm}$ (Fig. 7). The degree of hydrolysis increases as follows: HEMC I > HEMC II > HEMC III, which is directly dependent on the viscosity of the aqueous solutions of these ethers (Table 1). This result can be explained by the fact that in this series the degree of polymerization rises according to the evidenced increase of the viscosity of the aqueous HEMC solutions. Thus, when studying the hydrolysis process, a qualitative assessment of the degree of polymerization of cellulose ethers with the same structure can be obtained.

The assignment of signals in the ${ }^{13} \mathrm{C}$ NMR spectra was carried out using calculated data (Table 4). The classification of the signals in the ${ }^{13} \mathrm{C}$ NMR spectra was made by computation data (Table 3). Therefore, the signals at $\sim 96 \mathrm{ppm}$ in all the spectra correspond to $\beta$-hemiacetal carbon atoms, when the signals of $\alpha$-hemiacetal carbon atoms are at $\sim 92 \mathrm{ppm}$. The chemical shifts of C-2 and C-3 atoms, which substituted acidic hydrogen, differ significantly from the analogical atoms without substituted hydroxyl group. The chemical shifts of C-4 and C-5 atoms don't differ greatly for various types of derivatives and are in the range of 69-72 ppm (for C-4) and 75-80 ppm (for C-5). The value of the chemical shift of C-6 atom depends rather strongly both on the presence of the substituent in the hydroxyl group and on its type. The chemical shift of the carbon atom in the methoxyl group is in the range of 57-59 ppm. The carbon atoms of the hydroxyethyl fragment differ greatly: 60-62 ppm (for $-\mathrm{CH}_{2}-\mathrm{OH}$ ) and 69-71 ppm (for - $-\mathrm{CH}_{2}-$ ). The correct assignment of the secondary carbon atoms signals is confirmed by DEPT135 experiment (Fig. 8).

The degree of substitution of the hydroxyl group at C-2 position $\left(D S^{C-2}\right)$ can be calculated as the ratio of the $\mathrm{C}-2$ signal integral intensity in the presence of substituted hydroxyl group ( $~ 89.6$ $\mathrm{ppm})$ to the total intensity of all the signals belonging to partially acetal carbon atoms, in accordance with Equation 2:

$$
D S^{C-2}=\frac{\alpha I_{89.6}}{I_{96.0-96.2}+I_{92.3}}
$$

The degree of substitution of the hydroxyl group at the C-3 position $\left(D S^{C-3}\right)$ can be calculated as the ratio of the $\mathrm{C}-3$ signal integral intensity in the presence of the substituted hydroxyl group $(\sim 85.0-85.6 \mathrm{ppm})$ to the total intensity of all the signals corresponding to partially acetal carbon atoms, in accordance with Equation 3:

$$
D S^{C-3}=\frac{\alpha I_{84.5-85.0}}{I_{96.0-96.2}+I_{92.3}}
$$




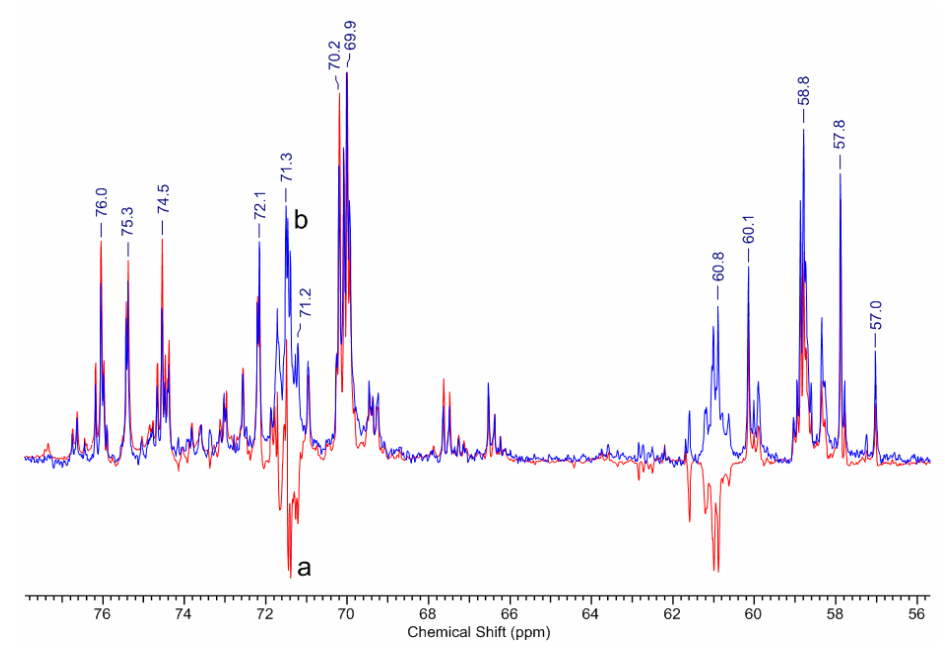

Figure 8: ${ }^{13} \mathrm{C}$ NMR spectra of the products of acid-catalyzed hydrolysis of HEMC II samples in $\mathrm{D}_{2} \mathrm{O} / \mathrm{H}_{2} \mathrm{O}$ $\left(4 \% \mathrm{HClO}_{4}, 90 \mathrm{~min}, 110^{\circ} \mathrm{C}\right)$ : a - DEPT135 spectrum, b - normal spectrum

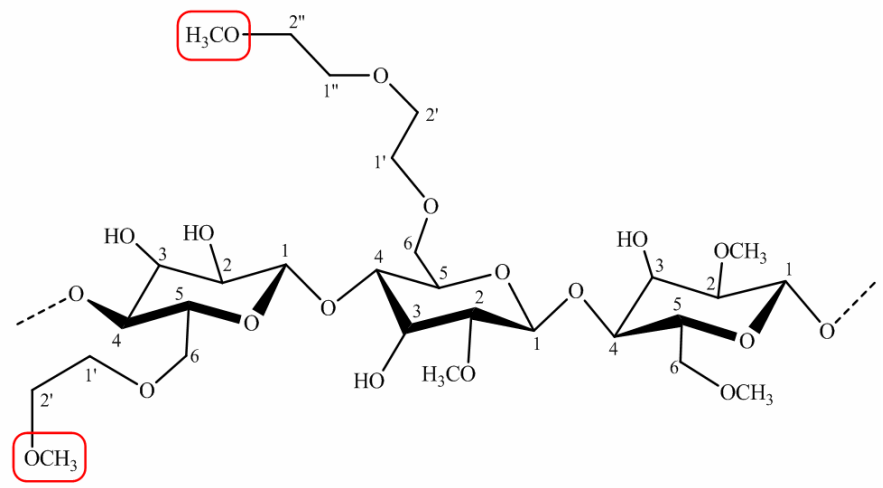

Figure 9: Fragment of hydroxyethyl methylcellulose molecule

The degree of substitution of the hydroxyl group at the C-6 atom in HEMC $\left(D S^{C-6}\right)$ can be calculated by comparing the signal intensities of unsubstituted and substituted C- 6 atoms, their chemical shifts differ significantly. The signals of unsubstituted C-6 atoms have a chemical shift at $\sim 59.5-61.3 \mathrm{ppm}$, and the signals of substituted C6 atoms are observed at $\sim 71.0-72.0 \mathrm{ppm}$, so the degree of substitution $D S^{C-6}$ can be calculated in accordance with Equation 4:

$D S^{C-6}=\frac{\alpha I_{71.0-71.5}}{I_{71.0-71.5}+I_{59.5-61.3}}$

The total degree of substitution for all the samples of HEMC $\left(D S^{\text {total }}\right)$ is the sum of all the degrees of substitution of the hydroxyl groups at C-2, C-3 and C-6 positions (Eq. 5):

$D S^{\text {total }}=D S^{C-2}+D S^{C-3}+D S^{C-6}$

The total degree of substitution of the hydroxyl group with methyl radicals $D S^{M e}$ is the ratio of the total intensity of all the signals belonging to methoxy groups ( 57.5-59.2 ppm) to the total intensity of partially acetal carbon atoms (Eq. 6):

$D S^{M e}=\frac{\alpha I_{57.5-59.2}}{I_{96.0-96.2}+I_{92.3}}$

It is worth mentioning the possibility of hydroxyl substitution in the hydroxyethyl fragment, which can lead to the generation of cellulose ether with the structure shown in Figure 9.

To determine the amount of the methyl fragments bonded with the hydroxyethyl groups $D S_{H E}^{M e}$, it is proposed to calculate the total substitution of the hydroxyethyl fragments of the glucopyranose unit, in accordance with other data, and then calculate the mentioned parameter as a difference. 
Hydroxyethyl methylcellulose

Table 5

Resulted calculations of substitution parameters for HEMC (I-III)

\begin{tabular}{ccccccccc}
\hline HEMC & DS $^{\mathrm{HE}}$ & $\mathrm{DS}^{\mathrm{Me}}$ & $D S_{H E}^{M e}$ & $\mathrm{DS}^{\mathrm{C}-2}$ & $\mathrm{DS}^{\mathrm{C}-3}$ & $\mathrm{DS}^{\mathrm{C}-6}$ & DS $^{\text {total }}$ & $\mathrm{DS}^{\mathrm{N}}[21]$ \\
\hline I & 0.42 & 1.02 & 0.18 & 0.55 & 0.22 & 0.62 & 1.39 & $\sim 1.4$ \\
II & 0.49 & 1.11 & 0.20 & 0.58 & 0.24 & 0.69 & 1.51 & $\sim 1.5$ \\
III & 0.67 & 1.26 & 0.23 & 0.64 & 0.29 & 0.73 & 1.7 & $\sim 1.7$ \\
\hline
\end{tabular}

The total degree of hydroxyl substitution with hydroxyethyl groups for HEMC samples $D S^{H E}$ can be calculated as the ratio of the intensity of all the carbon atoms in the hydroxyethoxyl fragments, except the end group $\left(\mathrm{CH}_{2} \mathrm{OH}\right)(60.0-$ $61.0 \mathrm{ppm}$ ), to the total intensity of unsubstituted C-6 atoms and the end carbon atoms of hydroxyethyl fragments $\left(\mathrm{CH}_{2} \mathrm{OH}\right)$ (60.0-61.0 ppm), including the substituted C-6 atom (71.072.0 ppm) (Eq. 7):

$$
D S^{H E}=\frac{I_{60.0-61.0}}{I_{71.0-72.2}+I_{60.0-61.0}}-D S^{C-6}
$$

Then, the degree of substitution of the hydroxyethyl fragment with methyl radicals $D S_{H E}^{M e}$ can be calculated in accordance with the following condition: if the common degree of substitution with methoxyl groups $D S^{M e}$, calculated according to Equation 6, is greater than the value of the difference $D S^{\text {total }}-D S^{H E}$, then the additional substitution to the methyl radical in the hydroxyethyl fragment has taken place. It can be quantified according to Equation 8:

$D S_{H E}^{M e}=D S^{M e}-D S^{\text {total }}-D S^{H E}$

The resulted calculations of the substitution parameters for the investigated samples (I-III) of hydroxyethyl methylcellulose are shown in Table 5. Partial hydroxyl substitution of 2hydroxyethoxy fragments is observed for all the samples, reaching $32-43 \%$, because of the higher reactive capacity of primary hydroxyl. Overall, the total DS values of the investigated ethers fit well with the values indicated by the manufacturers. Thus, it is possible to claim that ${ }^{13} \mathrm{C}$ NMR spectroscopy of the products formed in the process of acid-catalyzed hydrolysis of HEMC can be used for determining the polymer's structure, distribution of substituents at C-2, C-3 and $\mathrm{C}-6$ positions of the glucopyranose unit and degree of substitution.

\section{CONCLUSION}

In this work, the structure of hydroxyethyl methylcellulose, represented by three commercial samples of cellulose ethers, was defined according to the products of their acid-catalyzed hydrolysis under the action of perchloric acid. To find the solution in question of the assignment of chemical shifts to different carbon atoms of HEMC, calculations with the help of the BIOPSEL program were carried out. The signals were assigned on the basis of the obtained values, and an approach to calculations of the substitution parameters of the anhydroglucose unit was proposed. The precise data on the degree of substitution in the positions 2,3 and $6\left(\mathrm{DS}^{\mathrm{C}-2}\right.$, $\mathrm{DS}^{\mathrm{C}-3}$ and $\mathrm{DS}^{\mathrm{C}-6}$, respectively) and the total degree of substitution, $\mathrm{DS}^{\text {total }}$, were calculated. It was shown that the positions C-6 and C-2 and the hydroxyl of the hydroxyethyl fragment have the highest reactive capacity. The completeness of the hydrolysis increases in the following order: I $>$ II > III, which is directly dependent on the molecular weight of the polymers. So, taking into account the importance of the DS determination and the distribution of substituents as the most significant parameters of cellulose ethers, a universal and quite precise analysis of these key parameters was carried out. In further work, it is planned to investigate other mixed cellulose ethers, in particular, commercial samples of methyl hydroxypropylcellulose.

\section{REFERENCES}

T. Rosenau, A. Potthast and J. Hell (Eds.), "Cellulose Science and Technology: Chemistry, Analysis, and Applications", Wiley, 2018, 480 p., https://onlinelibrary.wiley.com/doi/book/10.1002/9781 119217619

2 Ch. Chang and L. Zhang, Carbohyd. Polym., 84, 40 (2011), https://doi.org/10.1016/j.carbpol.2010.12.023

W. Kaialy and M. Al Shafiee, Adv. Colloid Interface Sci., $\quad \mathbf{2 2 8}, \quad 71 \quad$ (2016), https://doi.org/10.1016/j.cis.2015.11.010

4 J.-Y. Petit and E. Wirquin, Int. J. Adhes. Adhes., 40, 202

https://doi.org/10.1016/j.ijadhadh.2012.09.007

5 Z. H. Ou, B. G. Ma and S. W. Jian, Constr. Build. Mater., 33, $\quad 78 \quad$ (2012), https://doi.org/10.1016/j.conbuildmat.2012.01.007

6 C. Brumaud, H. Bessaies-Bey, C. Mohler, R. Baumann, M. Schmitz et al., Cem. Concr. Res., 53, 176

(2013),

https://doi.org/10.1016/j.cemconres.2013.06.010 
7 A. Pierre, A. Perrot, V. Picandet and Y. Guevel, Cem. Concr. Res., 72, $117 \quad$ (2015), https://doi.org/10.1016/j.cemconres.2015.02.013

R. B. Chavan, S. Rathi, V. G. S. S. Jyothi and N. R. Shastri, Asian J. Pharm. Sci., 14, 248 (2019), https://doi.org/10.1016/j.ajps.2018.09.003

9 A. Balan, A. Moise and A. Grigoriu, Cellulose Chem. Technol., 44, $231 \quad$ (2010), http://www.cellulosechemtechnol.ro/pdf/CCT44,78(2010)/P.231-238.pdf

10 P. Mischnick and D. Momcilovic, Adv. Carbohyd. Chem. Biochem., 64, $117 \quad$ (2010), https://doi.org/10.1016/S0065-2318(10)64004-8

11 Z. Wang, "Comprehensive Organic Name Reactions and Reagents", Wiley, 2010, https://onlinelibrary.wiley.com/doi/book/10.1002/9780 470638859

12 H. Li, X.-S. Chai, H. Zhan, M. Liu and S. Fu, Anal. Lett., $\quad \mathbf{4 5}, \quad 1028 \quad$ (2012), https://doi.org/10.1080/00032719.2012.670783

13 R. Adden, R. Müller and P. Mischnick, Cellulose, 13, 459 (2006), https://doi.org/10.1007/s10570-0059028-X

14 P. Mischnick, I. Unterieser, K. Voiges, J. Cuers, M. Rinken et al., Macromol. Chem. Phys., 214, 1363 (2013), https://doi.org/10.1002/macp.201300070

15 J. A. Cuers, M. B. Rinken, R. C. Adden and P. Mischnick, Anal. Bioanal. Chem., 405, 9021 (2013), https://doi.org/10.1007/s00216-013-7065-0

16 R. Adden, W. Niedner, R. Müller and P. Mischnick, Anal. Chem., 78, $1146 \quad$ (2006), https://doi.org/10.1021/ac051484q

17 J. Kunze, A. Ebert and H. P. Fink, Cellulose Chem. Technol., $\quad 34, \quad 21 \quad$ (2000), http://www.cellulosechemtechnol.ro/onlinearticles.php 18 I. Nehls, W. Wagenknecht, B. Philipp and D. Stscherbina, Prog. Polym. Sci., 19, 29 (1994), https://doi.org/10.1016/0079-6700(94)90037-X

19 A. Karrasch, C. Jäger, B. Saake, A. Potthast and T. Rosenau, Cellulose, 16, $1159 \quad$ (2009), https://doi.org/10.1007/s10570-009-9304-2
20 S. V. Araslankin, V. A. Kalyazin, S. G. Kostryukov and P. S. Petrov, Khimiya Rastitel'nogo Syr'ya, 1, 51 (2019), https://doi.org/10.14258/jcprm.2019014127

21 S. G. Kostryukov, S. V. Araslankin, P. S. Petrov, V. A. Kalyazin and A. A. I. Al-Rubaye, Izvestiya Vysshikh Uchebnykh Zavedenii, Seriya Khimiya $i$ Khimicheskaya Tekhnologiya, 62, 102 (2019), https://doi.org/10.6060/ivkkt.20196208.5910

22 A. Martínez-Richa, Carbohyd. Polym., 87, 2129 (2012), https://doi.org/10.1016/j.carbpol.2011.10.039

23 S. G. Kostryukov, S. V. Araslankin and P. S. Petrov, Khimiya Rastitel'nogo Syr'ya, 4, 31 (2017), https://doi.org/10.14258/jcprm.2017041860

24 https://www.setylose.com

25 https://toukach.ru/files/biopsel.zip

26 F. V. Toukach and V. P. Ananikov, Chem. Soc. Rev., 42, $\quad 8376 \quad$ (2013), https://doi.org/10.1039/c3cs60073d

27 A. Trummal, L. Lipping, I. Kaljurand, I. A. Koppel and I. Leito, J. Phys. Chem. A, 120, 3663 (2016), https://doi.org/10.1021/acs.jpca.6b02253

28 H. Müller, "Sulfuric Acid and Sulfur Trioxide", in "Ullmann's Encyclopedia of Industrial Chemistry", Wiley, 2000 , https://onlinelibrary.wiley.com/doi/abs/10.1002/14356 007.a25_635 